\title{
ENSINO INTERATIVO DE FÍSICA UTILIZANDO MATERIAIS DE BAIXO CUSTO E FÁCIL ACESSO
}

Silvio Luis Agostinho Dos Santos

Universidade Estadual Paulista Júlio Mesquita Filho - UNESP - Presidente Prudente, SP. E-mail: silvioluisagostinho@gmail.com.

\section{RESUMO}

Neste artigo, descrevemos uma metodologia de ensino de Física que foi implementada no Ensino Médio na ETEC Profo Eudécio Luiz Vicente localizada na cidade de Adamantina, SP. A proposta valoriza a compreensão da ciência como produção humana e fundamenta o processo ensino de uma aprendizagem significativa segundo David Ausubel e na atividade experimental, de modo a articular o conhecimento formal da Física com os saberes do aluno. Neste trabalho foi apresentada uma proposta de inserção de experimentos de baixo custo e fácil acesso, no ensino de Física. Foram realizados experimentos de Física, em que o aprendiz pudesse alcançar a compreensão das Leis da Física. No final o produto educacional foi o desenvolvimento de 03 Kits de Experimentos portáteis. 0 envolvimento dos alunos foi, inicialmente, empolgante para a realização dos experimentos e o rendimento escolar e a satisfação dos alunos foi maior.

Palavras-chave: Aprendizagem Significativa, Feira Científica de Física e Kit de Experimentos.

\section{INTERACTIVE PHYSICAL EDUCATION USING LOW COST AND EASY ACCESS MATERIALS}

\begin{abstract}
I
In this article, we describe a methodology of Physics teaching that was implemented in High School at ETEC Prof. Eudécio Luiz Vicente located in the city of Adamantina, SP. The proposal values the understanding of science as human production and bases the teaching process of a meaningful learning according to David Ausubel and in the experimental activity, in order to articulate the formal knowledge of Physics with the student's knowledge. In this work we present a proposal for the insertion of low cost and easy access experiments in physics teaching. Physics experiments were conducted, in which the learner could achieve an understanding of the Laws of Physics. In the end the educational product was the development of 03 Portable Experiment Kits. Student involvement was initially exciting for the experiments and school performance and student satisfaction was greater.
\end{abstract}

Keywords: Significant Learning, Scientific Fair of Physics and Experiment Kit. 


\section{INTRODUÇÃO}

As mudanças comportamentais da sociedade e o advento da tecnologia estão levando os docentes a buscar uma forma de ensino que seja distinta da tradicional, as atividades experimentais em sala de aula, podem se constituir de um complemento metodológico cativante para despertar o interesse e motivar os alunos para o desenvolvimento científico e na melhoria da qualidade do ensino.

De acordo com David Ausubel (2003), existe uma série de atitudes que o professor necessita ter para colaborar com uma aprendizagem significativa, a saber: redução de soluções prontas, desafios aos alunos e aprofundamento da aprendizagem.

Para Ausubel, o aluno deve ser protagonista da aprendizagem, por isso recomenda o uso de "organizadores prévios" como estratégia de ensino-aprendizagem. A construção de experimentos por parte do aluno tem por objetivo propiciar que os alunos participem da construção do conhecimento.

A construção e desenvolvimento de experimentos levam à aprendizagem significativa, desafiando os alunos, pois os mesmos não têm soluções prontas o que leva ao despertar para o desenvolvimento científico, aprofundando sua aprendizagem de maneira lúdica e empolgante.

A montagem de kits de experimentos, utilizando materiais de baixo custo e fácil acesso, ajuda os alunos a organizarem suas ideias sobre os experimentos e desenvolvem o cognitivo em relação a transposição deste conhecimento, assim como, a apresentação dos experimentos, que constam nestes kits, através da organização de uma Feira Científica de Física. Deste modo os alunos aprendem não só conceitos de Física, mas a interação e solidariedade entre seus pares, uma vez que aprender os conceitos é uma fase do aprendizado e transmitir o conhecimento é outra fase que depende de outros fatores e desenvolve o aluno como um cidadão inserido em uma sociedade.

Como contribuição desse trabalho: uma proposta para a utilização de atividades experimentais no ensino de Física no nível médio através de uma abordagem dialógica, no desenvolvimento de sequência didática para cada assunto de física, material de apoio em uma página da internet, por consequência os alunos irão atingir uma aprendizagem significativa e uma primeira experiência para um maior investimento futuro em iniciativas de formação inicial e continuada.

\section{OBJETIVOS}

Neste trabalho, é feita uma proposta para apresentação dos conteúdos abordados no Ensino Médio através de experimentos, sendo que a utilização dos kits de experimentos foi utilizada no laboratório de ciências da unidade escolar, no contra turno. O material, desenvolvido para este fim, consiste em um site de apoio ao projeto, a realização de uma Feira Científica de Física e a produção de um kit de experimentos para cada série do Ensino Médio. A escolha do tema deu-se da percepção da carência de material didático voltado ao Ensino Médio e, também, pela facilidade de se produzirem experiências simples, utilizando materiais de baixo custo e fácil acesso, como materiais recicláveis e também sucata de aparelhos eletrônicos.

Ao final do processo, espera-se que o estudante tenha formado uma base conceitual para investigar problemas mais complexos do conteúdo abordado. Além disso, espera-se que tenham ficado claras para ele, a diferença e a conexão entre a experiência e os modelos matemáticos, com isso adquirindo uma aprendizagem significativa. Com o desenvolvimento experimental, espera-se, portanto: 
- Estimular o aluno pela descoberta científica e a vivência dos fenômenos físicos, relacionar através das observações realizadas na Natureza.

- Construir Kits de Experimentos para Física no Ensino Médio, de forma interativa, para conduzir uma aprendizagem significativa, crítica e consistente desta disciplina.

- Utilizar sequências didáticas e trabalhar com temas atuais que envolvem conceitos da Física no cotidiano.

- Reunir os saberes docentes e a metodologia adotada em um instrumento de apoio ao professor.

\section{METODOLOGIA}

No início do trabalho, foi elaborado um questionário para levantamento de dados relacionados ao interesse dos alunos pela Física, seus conteúdos e eventuais participações em atividades diferenciadas. A elaboração desse primeiro questionário foi baseada no artigo de Ricardo e Freire (2007). Nesse artigo foi discutido o resultado de um estudo feito com alunos do Ensino Médio e o objetivo era identificar suas concepções acerca do ensino da Física. Com base no resultado do trabalho destes autores, foram organizadas algumas questões visando verificar a importância da Física no cotidiano dos estudantes participantes do presente trabalho.

Portanto, o objetivo principal do questionário utilizado para esta pesquisa é verificar a opinião dos alunos acerca do ensino atual da Física e, com isso, o questionário oportunizou conhecer as dificuldades encontradas pelos alunos para buscar metodologias diferenciadas, na busca de um maior conhecimento nos conteúdos abordados em física no ensino médio. Os resultados referentes ao $1^{\circ}$ Questionário são mostrados a seguir.

A Figura 1 mostra resultados da opinião dos estudantes relacionada às dificuldades encontradas no aprendizado dos conteúdos da Física. Os resultados para esta questão mostram que $39 \%$ deles não entendem os cálculos, $24 \%$ não conseguem interpretar a teoria, $10 \%$ não conseguem relacionar a teoria e a prática e outros $27 \%$ atribuem essa dificuldade à forma como a disciplina é mediada pelo professor. Os resultados apresentados nesta questão implementou a ideia inicial de utilizar uma metodologia diferente, aliada à uma sequência didática para os conteúdos abordados em sala de aula, além da utilização da experimentação. Este conjunto de ações vinculadas ao ensino de Física buscou diminuir as dificuldades apontadas pelos estudantes nesta questão de opinião.

Figura 1. Quais as dificuldades no aprendizado em física.

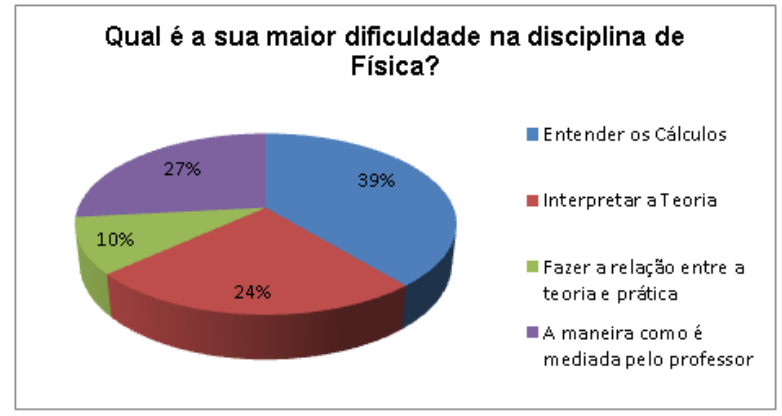

Fonte: (Autor, 2015).

Um trabalho semelhante foi realizado anteriormente (VALÉRIO, 2015) e, comparativamente, os resultados mostram que as opiniões dos estudantes são similares. Esta comparação leva à insistência em defender o princípio de que uma nova postura 
profissional se faz necessária para atender a um público diversificado e que almeja um sistema de educação de boa qualidade de útil para sua vivência social e cultural.

Com a identificação das dificuldades dos alunos através do pré-questionário, foi possível elaborar várias sequências de aulas sobre aplicações práticas "Ensino Interativo de Física utilizando materiais de baixo custo e fácil acesso". Foi abordada ainda, na sequência didática, a presença da Física no cotidiano, a fim de despertar o conhecimento científico e focar as expectativas a respeito do assunto desenvolvido em sala de aula e no laboratório de ciências.

Todas as montagens dos experimentos realizados ficaram por conta dos alunos, que foram separados em turmas, conforme seu nível de ensino. A montagem dos experimentos foi realizada no laboratório de ciências da Unidade Escolar.

\section{RESULTADOS}

Após o desenvolvimento das sequências didáticas e todos os experimentos, que estão disponíveis no site de apoio do projeto de experimentos através do seguinte endereço http://experimentos-de-fisica.webnode.com/experimentos e a aplicação das atividades experimentais pertinentes para cada série do Ensino Médio, foi aplicado o 20 Questionário Questionário Final do Aluno - cujo objetivo principal foi verificar se houve um aumento no interesse pela Física, suas menções aumentaram após sua participação no projeto e, também, se a metodologia utilizada nas sequências didáticas, houve um avanço significativo nos processos de ensino e aprendizagem, de acordo com as menções apresentadas.

A Figura 2 faz um comparativo das menções dos estudantes, na disciplina de Física antes e depois de terem participado no projeto de experimentos. Temos um aumento de $11 \%$ dos alunos com conceito muito bom, $17 \%$ dos alunos melhoraram seu conceito para bom, $23 \%$ que tinham conceito regular, melhoraram seus conceitos para bom e muito bom e $0 \%$ nenhum aluno teve conceito insatisfatório. A metodologia utilizada no laboratório de ciências da unidade escolar na aplicação das sequências didáticas com a realização de vários experimentos conseguiu sanar a defasagem nos conteúdos e por consequência houve uma melhora significativa nas menções apresentadas pelos estudantes.

Figura 2. Comparação da Menção dos alunos em Física.

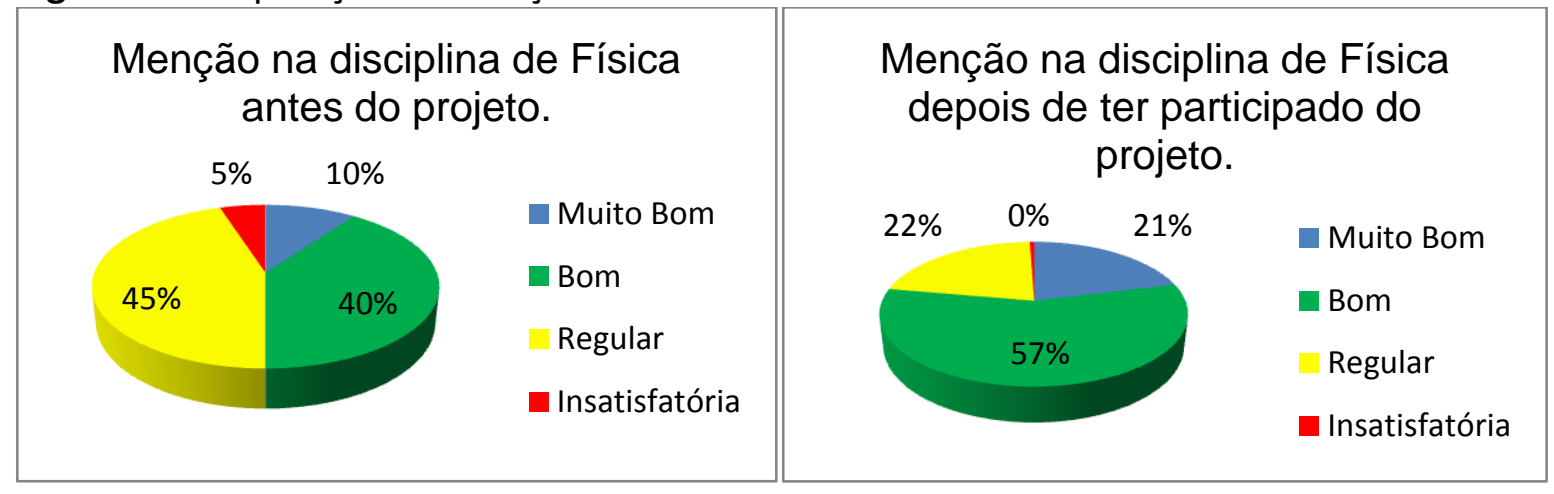

Fonte: (Autor, 2015).

\section{DISCUSSÃO}

Fazendo uma análise indutiva das respostas dos questionários propostos, foi possível observar a mudança na concepção dos alunos com relação às aulas de Física e um aumento significativo nas menções dos alunos, também o reconhecimento da importância do conhecimento em Física no cotidiano dos estudantes. 
A comparação destes resultados leva ao fato conclusivo de que adotar novas maneiras de ensinar a Física e trazê-la para o convívio real dos alunos é a maneira mais adequada e eficiente para um processo de ensino-aprendizagem significativo, como proposto por Ausubel.

Para estabelecer as perspectivas em relação ao processo de ensino e aprendizagem como resultado de aulas com atividades experimentais dialógicas de caráter investigativo, é necessário estar atentos ao desenvolvimento de algumas de suas características, entretanto, antes de apresentar as conclusões sobre o este assunto abordado, como as atividades experimentais e as sequências didáticas foram importantes, que esse trabalho incorporou.

A grande maioria dos alunos de Física no Ensino Médio brasileiro não tem aulas experimentais ou as têm em pouquíssimas oportunidades, segundo (HODSON, 1988), evidenciando que a velocidade com que os trabalhos sobre o tema são publicados é muito maior que a de chegada do conteúdo destes em sala de aula. Aplicar atividades experimentais mesmo em uma metodologia diferente da que aqui foi apresentada já consiste em um avanço para tirar os estudantes de uma inércia teórica presente na escola média atual.

A partir das atividades desenvolvidas no 10 e 20 Semestre de 2015 dentro do Projeto de Experimentos no Laboratório de Ciências da unidade escolar, contemplando as seguintes Leis da Física: Mecânica, Óptica, Termologia, Eletricidade, Magnetismo e Eletromagnetismo, observou-se que o projeto de um Kit didático para experiências de Física no Ensino Médio seria de grande valia para os mesmos, facilitando tanto a vida dos professores ao ensinar, como para os alunos que participam mais ativamente do processo de ensino-aprendizagem.

As sequências didáticas que abordam o assunto teórico e os procedimentos dos experimentos estão disponíveis no site do Projeto de Experimentos através do endereço http://experimentos-de-fisica.webnode.com e, também, o Kit propriamente dito, fazem parte desse material. Os pontos fortes são: a simplicidade em montar os experimentos e o baixo custo dos componentes, sendo de fácil obtenção no mercado. Essas facilidades fazem desse Kit, um bom acessório para ser adotado nas escolas públicas.

A sequência didática dá todos os passos necessários à boa realização experimental, sendo que, antes de cada série de experimentos, é dada uma breve revisão teórica sobre o assunto tratado. Dessa forma, o aluno terá subsídios para conduzi-los de forma clara e didática. Uma observação a ser feita é que esse material não deve ser a única fonte de pesquisa sobre esses temas. Outras fontes devem ser utilizadas, uma vez que ele foi concebido para complementar a temática teórica dada pelo professor. Logo em seguida, são abordados os objetivos, os materiais do experimento e em seguida, a parte experimental propriamente dita.

O Kit de experimentos foi implementado no formato de uma mala de viagem. São 3 Kits distintos, sendo cada um referente a uma série do Ensino Médio (1ํAno, 2ํAno e 3Ano), contendo componentes diversos e de fácil aquisição em sua maioria.

Os Kits foram utilizados nas aulas práticas realizadas em sala de aula e no laboratório de ciências da unidade escolar. Eles organizaram e facilitaram o transporte dos materiais necessários para a realização dos experimentos. Os experimentos foram realizados em tempo adequado. Pode-se constatar que os Kits experimentais possuem uma valiosa serventia para que as aulas práticas sejam uma constante no cotidiano escolar e que todos os produtos desenvolvidos neste projeto sirvam de auxilio para os professores e alunos em sua aprendizagem. 
Figura 3. Kit de Experimentos da Turma da 3ạ Série do Ensino Médio

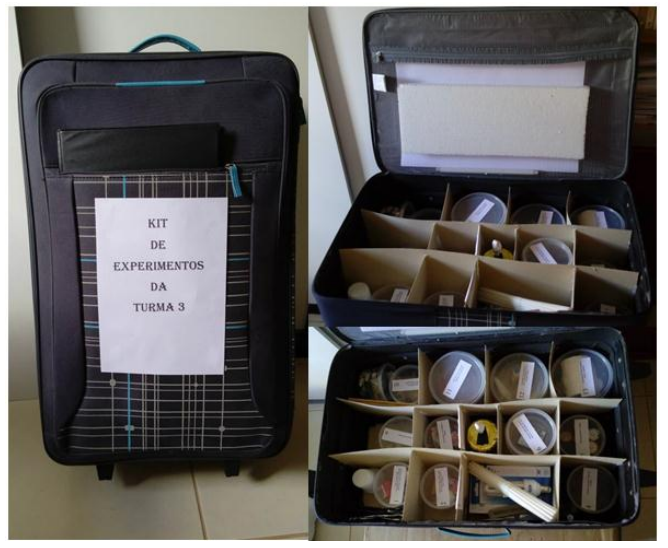

Fonte: (Autor, 2015).

\section{CONSIDERAÇÕES FINAIS}

Apesar de não ser tema central desta pesquisa, defende-se a proposta de um maior investimento do tema em disciplinas específicas da formação inicial do professor de Física e em cursos de pós-graduação em Ensino de Ciências, bem como em iniciativas de formação continuada.

A problematização dos conteúdos durante as atividades experimentais se mostrou um instrumento eficiente no desencadeamento de dois aspectos importantes do processo de ensino e aprendizagem. Em primeiro lugar, ela pode ser uma ferramenta poderosa para o professor que deseja conhecer as concepções alternativas dos alunos em relação a determinado tema bem como se desejar produzir, com o debate, conflitos cognitivos numa intensa comparação entre os modelos pré-existentes e os conteúdos científicos.

Entende-se que essa interpretação, de orientação construtivista, estabelece uma relação entre aluno, professor, atividade e os aspectos cognitivos da aprendizagem. $\mathrm{O}$ aluno aprende melhor quando confronta o que sabe, aprendido durante toda sua existência, com resultados que podem ser diferentes de sua concepção. Neste momento, cabe ao professor dominar os instrumentos pedagógicos para mediar com maior eficiência possível o embate. Os processos de mudança conceitual são lentos e precisam de continuidade para acontecer.

O nível de satisfação dos alunos, durante as atividades, manifesta um ambiente propício à aprendizagem onde todos são agentes do processo, agindo como pesquisadores com uma investigação própria. Conclui-se que o nível de rupturas das concepções antigas e a substituição por outras, não necessariamente científicas, mas, pelo menos mais elaboradas, foi satisfatório e promovido pelos conflitos cognitivos e interações sociais promovidos durante a aplicação das atividades. Uma continuidade desse trabalho poderia, sim, criar condições para um aprendizado de Ciência em que as mudanças conceituais para modelos científicos fossem atingidas em médio prazo.

Resumidamente, menciona-se como contribuição desse trabalho: uma proposta para a utilização de atividades experimentais no ensino de Física no nível médio através de uma abordagem com sequências didática e uma primeira experiência para um maior investimento futuro em iniciativas de formação inicial e continuada.

A comparação destes resultados leva ao fato conclusivo de que adotar novas maneiras de ensinar a Física e trazê-la para o convívio real dos alunos é a maneira mais adequada e eficiente para um processo de ensino-aprendizagem significativo, como proposto por Ausubel. 
Os kits de Experimentos desenvolvidos no projeto na unidade escolar ficaram como um produto educacional para que outros professores possam utilizar em suas aulas de física.

\section{REFERÊNCIAS BIBLIOGRÁFICAS}

AUSUBEL, D. P. A aprendizagem significativa: a teoria de David Ausubel. São Paulo: Moraes, 2003.

HODSON, D. Towards a philosophically more valid science curriculum. Science Educacion, v. 72, n.1, 1988.

RICARDO, E. C.; FREIRE, J. C.A. A concepção dos alunos sobre a física do ensino médio: um estudo exploratório.

Revista Brasileira de Ensino de Física, v. 29, n. 2, 2007. p. 251-266.

https://doi.org/10.1590/S1806-11172007000200010

VALÉRIO, R. C. Os Fundamentos da Física Aplicados em Situações Cotidianas: Um Estímulo para Aumentar o Interesse dos Alunos. 2015. Dissertação (Mestrado) - UNESP - FCT Campus de Presidente Prudente, SP. Disponível em: <https://repositorio.unesp.br/bitstream/handle/11449/135909/000857813.pdf>. Acesso 10 julho 2018. 